REFLEXIÓN

Recibido: 25/09/2013

Revisado: 25/10/2013

Aprobado: 25/11/2013

\title{
EL CONTRAPODER, HACIA UNA TEORÍA DEL EMPODERAMIENTO SOCIAL
}

\author{
ROBERTO MORA MARTÍNEZ \\ Centro de Investigaciones sobre América Latina y el Caribe -CIALC- \\ Universidad Nacional Autónoma de México -UNAM
}

\begin{abstract}
RESUMEN
El término "Contrapoder" surgido del deseo por la creación de una praxis política productiva, será el referente primordial en el análisis de Roberto Mora Martínez, acogiendo las Mediaciones Dialécticas de Joaquín Sánchez Macgrégor, señalando que "la política puede ser concebida como una lucha o como elemento de integración". Una filosofía política aplicada, puesta en escena sobre la lucha del Poder Estatal, en un meticuloso ejercicio del Contrapoder de una manera activa y no violenta, un ideal que mientras el poder político se ejerce en beneficio de una minoría instalada en los puestos de control social "el Contrapoder busca el establecimiento de derechos y beneficios para las mayorías". Un estudio social que se apoya en esta y en múltiples propuestas unánimes, germinadas de la necesidad de "cambiar la forma de luchar" es decir, de acabar con un sistema basado en la propiedad privada, y la importancia de entender el contexto social del cual se desea prosperar, sin necesidad de ejercer la violencia como "arma de lucha".
\end{abstract}

Palabras clave: Contrapoder, Programa Político, Poder, Control Estatal.

\section{ABSTRACT}

The term "Counterpower" arising from the desire for the creation of a productive political praxis will be the main reference in the analysis of Roberto Mora Martínez, welcoming the Dialectical Mediations of Joaquín Sánchez Macgrégor, noting that "politics can be conceived as a struggle or As an element of integration". An applied political philosophy, staged on the struggle of the State Power, in a meticulous exercise of the Counterpower in an active and non-violent way, an ideal that while political power is exercised for the benefit of a minority installed in the social control posts "The Counter Power seeks the establishment of rights and benefits for the majority". A social study that is based on this and multiple proposals unanimous, germinated of the need to "change the way to fight", that is, to end a system based on private property, and the importance of understanding the social context of the Which one wishes to thrive, without having to exercise violence as a "weapon of struggle".

Key words: Counterpower, Political Program, Power, State Control. 


\section{Introducción}

Hoy día en México y América Latina han surgido gran número de movilizaciones sociales que están luchando por la reivindicación de sus derechos y de mayor bienestar para sus familias. Este activismo organizacional ha sido calificado como un despertar de las poblaciones. Así, se indica que la ciudadanía está cada vez más politizada, lo cual no es del todo cierto, ello se debe a que considero que la gente está respondiendo de manera activa a las acciones gubernamentales que están afectando negativamente su vida. Lo cual no implica que tengan una mayor conciencia política.

En este escrito expongo las principales características de la política, considerando el tema del poder y la relación que éste guarda con la propuesta del contrapoder, sobre todo en la concepción de Joaquín Sánchez Macgrégor. Ello, debido a que en este autor se encuentran ideas fundamentales para concretar una praxis política, a partir de su propuesta de creación de un programa político, lo cual le parece fundamental para evitar las actividades violentas, que en gran número de casos considera innecesarias.

\section{La política y el poder}

Como este es un escrito breve, sólo es necesario anotar unas breves notas sobre las principales características de la política. En opinión de Carina Gómez Fröde, desde épocas remotas se estableció una diferenciación entre gobernantes y gobernados, entre los que toman las decisiones y quienes las acatan. Sin embargo, como supuestamente, hoy día, cualquier persona puede ocupar los altos puestos en política, se dificulta la comprensión de las personas que ocupan los cargos de elección popular.

Debido a la posibilidad de que cualquier persona del pueblo ocupe cargos políticos, es que Giovanni Sartori tiene razón cuando señala que la propuesta de la democracia, aunque haya nacido con los griegos, en realidad es un aporte reciente, pues se busca que la decisión de la población sea acatada por aquellos elegidos para gobernar.

Sin embargo, la gente de la población está muy lejos de poder ocupar los más altos puestos de elección popular. Ello se debe a que es tal la cantidad de intereses prácticos y negociaciones que se deben establecer para ocupar uno de los cargos, que prácticamente se hace imposible que una persona que no pertenezca a una asociación política y, que además no le dé satisfacción a los intereses de los agremiados, pueda acceder a un cargo directivo.

Así, en términos generales "se acepta que la política es la lucha por el poder, tanto en el seno de una sociedad concreta como en el contexto más amplio de la sociedad en general"1. Lucha que en la actualidad, se caracteriza por la obtención del control estatal, la cual se ha dejado en manos de los partidos políticos, los cuales se conforman y actúan por intereses específicos. De ahí que cada una de los grupos que luchan organizadamente por obtener los cargos más altos, necesiten de gente obe-

1. Carina Gómez Fröde, Introducción a la teoría política, México, Oxford, 2005 [Textos Jurídicos Universitarios]. 
diente que siga el programa establecido desde las cúpulas.

Sin embargo, la contienda partidista no agota las concepciones de la política. En este sentido, es posible citar otras características de la política, en el caso de Maurice Duverger, quien escribió que "la política puede ser concebida como una lucha o como elemento de integración" ${ }^{2}$. Sin embargo, en este punto lo que me interesa destacar es el factor del poder, al cual se lo puede definir como "la influencia voluntaria que ejerce un individuo o un grupo sobre la conducta de otro individuo o grupo"3. Por otra parte, en opinión de Carina Gómez, específicamente el poder político se caracteriza por "tratarse de un poder que se ejerce sobre hombres libres"4.

La manera como se ejerce el control de seres humanos en libertad, es a través del control del Estado. Idea, esta última, que se refuerza con la propuesta de Adolfo Sánchez Vázquez, quien al exponer el tema de la praxis señala que "la actividad política gira en torno a la conquista, conservación, dirección o control de un organismo concreto como es el Estado. El poder es un instrumento de importancia vital para la transformación de la sociedad"s.

Al considerar la relación entre poder y política, desde la perspectiva de Adolfo Sánchez Vázquez, se echa de ver que, la praxis política persigue determinados

2. Maurice Duverger, citado por Carina Gómez, Ibíd., p. 2.

3. Ibíd., p. 4.

4. Ídem.

5. Adolfo Sánchez Vázquez, Filosofía de la praxis, $3^{\mathrm{a}}$ reimp., México, Siglo XXI, 2013 [Biblioteca del pensamiento socialista], p. 278. fines, de acuerdo con las clases sociales. De ahí que en cada caso concreto:

La realización de esos fines se halla (sic) condicionada por las posibilidades objetivas inscritas en la propia realidad. Una política que responda a estas posibilidades y que excluya todo aventurerismo, exige un conocimiento de esa realidad y de la correlación de clases para no proponerse acciones que desemboquen inexorablemente en un fracaso. La lucha tiene que ser, por tanto, consciente, organizada y dirigida, y la necesidad de librarla en esta forma explica la existencia de los partidos políticos ${ }^{6}$.

Influencia sobre seres humanos libres, la cual, sobre todo en el presente, se ha destinado al bienestar de una minoría, como lo señala Mario Magallón quien al analizar las características del Estado liberal, apunta que éste no necesariamente debe ser democrático. De hecho, apunta que "la historia hasta hoy muestra que la mayoría de las sociedades se organizan jerárquicamente y de modo desigual y antidemocrático"7.

Ahora bien, es debido a la falta de interés de los gobernantes para establecer equidad económica, de participación política, de aceptación de la diversidad cultural, sobre en todo en concepciones de impartición de justicia, que es necesario, por parte de los gobernados, crear formas alternativas de poder. De tal modo que, es en este punto, en donde ingresa la propuesta del contrapoder, principalmente, des-

6. Ibíd., p. 278.

7. Mario Magallón Anaya, La democracia en América Latina, México, CCyDEL-UNAM-Plaza y Valdés, 2003 [Democracia y Cultura], p. 286. 
de la perspectiva de Joaquín Sánchez Macgrégor, aunque también cito a Luis Villoro, quien también lo ha trabajado.

\section{El contrapoder}

En la obra del filósofo mexicano Joaquín Sánchez Macgrégor, la propuesta del contrapoder, como principio organizativo de los movimientos sociales, está inevitablemente vinculada con la noción de poder, constituyéndose así un juego conceptual poder/contrapoder, el cual "trata de una relación diádica de oposición únicamente conceptual, ya que en la práctica real no son incompatibles, ni se presentan separadas las instituciones del poder y las del contrapoder"8

Así, el contrapoder se identifica con la población organizada, ya sea por un movimiento que haya surgido de manera espontánea, de manera organizada o sociedad civil. Sin embargo, como no existe un movimiento único, son contrapoderes, pero se mantiene el empleo en singular por ser una propuesta de filosofía política. Ahora bien, en el contrapoder se tiende a tomar decisiones de manera horizontal, esto es, que la opinión de todos los integrantes o por lo menos de la mayoría, son tomadas en cuenta para la toma de la decisión final ${ }^{9}$.

Sánchez Macgrégor, con base en su filosofía política, señaló que el ideal del contrapoder consiste en establecer

8. J. Sánchez Macgrégor, Op. cit., p. 176.

9. A diferencia del Poder cuyas decisiones se toman y ejercen de manera vertical, esto es, una persona o grupo deciden y los demás tienen el deber de llevar a cabo de la mejor manera posible el plan establecido desde la cúpula. un diseño o modelo alternativo para el ejercicio del poder propuesto desde el contrapoder. Esto es, el mandar obedeciendo de origen aristotélico, puesto en práctica por el Ejército Zapatista de Liberación Nacional (EZLN). Así, mientras el poder político se ejerce en beneficio de una minoría instalada en los puestos de control social, el contrapoder busca el establecimiento de derechos y beneficios para las mayorías.

Para las ideas de Luis Villoro quien con respecto del contrapoder señala que "Todos los movimientos de raíz ética, en el campo de la política, han querido poner límites al poder estatal". ${ }^{10}$ Así, este pensador indica que las revoluciones liberales, las propuestas anarquistas y los socialismos, buscaron eliminar el poder impositivo. De ahí que señale la paradoja según la cual, todo "intento de terminar con la dominación $\mathrm{o}$, al menos de limitarla, requiere poder", ${ }^{11}$ el cual, sin embargo, no debe ser del mismo género, esto es, impositivo, ya que, de ser así, el círculo de violencia y dominación perdura.

La propuesta de Villoro se dirige a señalar la importancia de sustituir al poder que se impone, por el poder que se expone, esto es, evitar la sustitución de la voluntad ajena, a través del ejercicio sin trabas de la propia. Ahora bien, para Villoro hay dos maneras de ejercer el contrapoder de una manera activa y no-violenta:

Sus usos negativos: la huelga, la disidencia crítica, individual o colectiva, la resistencia organizada de grupos de la sociedad civil frente al Estado, la

10. L. Villoro, Op. cit., p. 85.

11. Idem. 
desobediencia civil, etc. Otras acciones son positivas; intentan reemplazar, en todos los espacios sociales, la imposición por la tolerancia, el conflicto por la cooperación, el enfrentamiento por la negación y el diálogo. Así como el máximo poder lleva consigo la máxima violencia, el máximo contrapoder tiende a establecer la mínima violencia ${ }^{12}$.

Para Villoro el pueblo, esto es, los individuos que pertenecen a distintas comunidades organizadas con cuyos fines se identifican y que, por lo tanto, constituyen la base de sus acciones para la consecución de sus demandas, no debe caer en los excesos del poder, así tiene que "desprenderse del interés personal de dominar y excluir a los demás, y convertir la propia acción en una afirmación del bien del todo; obliga, en su límite, a renunciar a la voluntad de poder para sí mismo"13.

Es justo citar el trabajo de Enrique Serrano ${ }^{14}$ quien señaló que el contrapoder es una forma de poder, por ello cuando un poder calificado de contrapoder plantea la abolición de todo poder se cae en una paradoja que manifiesta la intención de un grupo, independientemente de la bondad de sus intenciones, de suprimir a sus rivales o, en el mejor de los casos, de negar las razones que ellos pueden esgrimir.

El escrito de Luis Villoro avanza hacia las formas de accionar político por parte del pueblo, las cuales van desde el referéndum y el plebiscito, hasta las

12. Ibíd., p. 87.

13. Ibíd., p. 90.

14. Cf., Enrique Serrano G., "La relación trágica entre el poder y el valor", pp. 565 a 579, en Metapolítica, revista trimestral de teoría política, vol. 2, julioseptiembre 1998. estrategias del EZLN, debido a la lucha que sostiene contra la tendencia homogeneizadora del Estado liberal mexicano.

Apoyándose en las propuestas organizativas y de autonomía del EZLN, Villoro señala que sólo en comunidades pequeñas, donde todos sus integrantes pueden encontrarse y dialogar, puede decidirse directamente sobre los asuntos colectivos. A diferencia de la nación en donde la representación es inevitable así como "también lo es la tendencia a substituir la voluntad de los representados por sus representantes"15.

Por otra parte, Villoro, señala que cuando en la nación, el pueblo real es heterogéneo, está conformado por múltiples comunidades, organizaciones sociales, grupos, etnias y nacionalidades, por ello la diversidad de problemas es amplia. De tal modo que, no es factible esperar a que el Estado resuelva todos los conflictos sociales. De ahí la necesidad de cambiar la manera como hasta la fecha se están organizando las movilizaciones sociales, las cuales en buena medida privilegian la violencia.

Debido a la necesidad de cambiar la manera de luchar, es que regreso al planteamiento de Sánchez Macgrégor, quien señaló que es necesario tener en mente paradigmas diferentes a las propuestas provenientes del marxismo, para conducir de una manera distinta las movilizaciones sociales. Ello se debe, a que en las propuestas de tendencia marxista-socialista, se ha considerado que el cambio revolucionario consiste en la lucha de clases obrero-burgués, la

15. Luis Villoro, Op. cit., p. 340. 
cual sólo se resolvería, es decir, llegaría a su fin, cuando una clase, la de los trabajadores, venza y termine con la otra, los ricos, dueños.

Al considerar que la solución de los conflictos sociales sólo provendría mediante una lucha revolucionaria, es que un número considerable de las movilizaciones sociales ha privilegiado los actos violentos. Un punto que considero es necesario aclarar, es que la lucha planteada por Engels y Marx, apuntaba a la desaparición de las condiciones burguesas de producción. En el Manifiesto del Partido Comunista, se propone la destrucción de un régimen de propiedad privada que tiene por condición necesaria el despojo o, más bien, impedir a las mayorías sociales la adquisición de bienes materiales:

¿O queréis referirnos a la moderna propiedad privada de la burguesía?

Decidnos: ¿es que el trabajo asalariado, el trabajo de proletario, le rinde propiedad? No, ni mucho menos. Lo que rinde es capital, esa forma de propiedad que se nutre de la explotación del trabajo asalariado, que sólo puede crecer y multiplicarse a condición de engendrar nuevo trabajo asalariado para hacerlo también objeto de su explotación. La propiedad, en la forma que hoy presenta, no admite salida a este antagonismo del capital y el trabajo asalariado. Detengámonos un momento a contemplar los dos términos de la antítesis. [...] iY a la abolición de estas condiciones, llama la burguesía abolición de la personalidad y la libertad! Y, sin embargo, tiene razón. Aspiramos, en efecto, a ver abolidas la personalidad, la independencia y la libertad burguesa. ${ }^{16}$

Desde esta perspectiva, en mi opinión no necesariamente se trata de luchar contra las personas que viven en la burguesía, sino de acabar con un sistema basado en la propiedad privada, terminando así con las personas interesadas en mantenerlo. Por ese motivo, es importante comprender la situación social de la cual se desea avanzar, sin necesidad de ejercer la violencia como principal o como única arma de lucha.

Por este motivo, Sánchez Macgrégor emplea la propuesta de las mediaciones dialécticas diseñada por Hegel, como base para avanzar en las propuestas de lucha violenta. Una idea interesante, es que Sánchez Macgrégor apuntó que en el pensamiento del filósofo prusiano se "advirtió que lo verdadero y lo falso podían intercambiarse, en determinadas condiciones". ${ }^{17}$ De ahí que, en el enfrentamiento y sobre todo después de éste, de llegarse al triunfo y no estar preparados para el ejercicio del poder, los movimientos sociales, pueden convertirse en aquello contra lo que luchaban, esto es, convertirse en una tiranía.

Debido a la posibilidad de que un movimiento social se transforme en su contraparte, es que Sánchez Macgrégor, apoyándose en Henri Niel, uno de los hegelianos quien difundió las ideas ex-

16. K. Marx \& F. Engels, Manifiesto del Partido Comunista (1848). Digitalizado para el Marx-Engels Internet Archive por José F. Polanco en 1998. Retranscrito para el Marxists Internet Archive por Juan R. Fajardo en 1999. www.marxists.org/español/m-e/1840s/48manif.htm. Fecha de consulta 21 de mayo de 2013.

17. Joaquín Sánchez Macgrégor, Ideologías políticas y poder moral, Una crítica para el contexto latinoamericano, México, UNAM, 2000, p. 23. 
presadas en la Fenomenología del espíritu, escribió:

(...) hay mediación cuando hay comienzo y paso a un segundo término, de tal modo, que este sólo se da cuando se llega a él partiendo de otro término [...].

Ahí donde se da una relación entre dos términos diferentes y que uno de ellos está en relación con el otro, esta relación se llama mediación [...].

(...) no hay nada que no contenga lo inmediato y la mediación, de modo que estas dos determinaciones no están separadas ni son separables y su oposición se reduce a nada ${ }^{18}$.

A mi parecer en el punto número dos se reúnen los aspectos de la mediación señalados en los otros dos, esto es, en el tránsito de un primer punto a otro, hay una relación que impide la separación y, por lo tanto, la oposición. Así, la mediación se debe emplear como base de un punto intermedio, éste no debe de conducir, en primera instancia, ni a la pasividad ni a la lucha violenta. Por lo cual debe guiar al punto intermedio de la negociación, para la solución de conflictos.

Considero interesante señalar que la propuesta mediadora expuesta por Sánchez Macgrégor, fue la que extrajo de las enseñanzas establecidas por seres humanos de vida virtuosa. Mujeres y hombres que se relacionaron con el poder, incluso ocupando altos cargos directivos dentro del Estado, pero a diferencia de los integrantes de la llamada clase política, emplearon sus puestos de representación social para servir a sus conciudadanos.

18. Ibíd., pp. 33-34.
Las y los seres humanos de vida virtuosa, fueron agrupados por Sánchez Macgrégor en una lista o Aurea Catena, compuesta por: Bartolomé de Las Casas, Simón Bolívar, la Madre Teresa de Calcuta, Mahatma Gandhi, Martín Luther King Jr., Nelson Mandela y Aung San Suu Kyi. Seres humanos de virtudes ejemplares, de quienes es posible aprender, para construir propuestas que permitan la efectiva participación social.

Los personajes de la Aurea Catena, constituyen el ejemplo de una vida que, en palabras de Sánchez Macgrégor utilizó el poder moral, propuesto por Simón Bolívar, el cual, en términos actuales se caracteriza por imponer controles democráticos al ejercicio del poder, con el fin de servir a la población.

Ahora, considero que el mayor aprendizaje expuesto por Sánchez Macgrégor, fue el que recuperó de las estrategias de Nelson Mandela, quien propuso el establecimiento de congresos locales, en cada una de las poblaciones de Sudáfrica, cuyo fin era el de discutir los problemas de interés social, llegar a una alternativa y que ésta se difundiera a los otros congresos. De esta propuesta, Sánchez Macgrégor indica la importancia del programa político.

\section{Programa político ${ }^{19}$}

Es importante señalar que Sánchez Macgrégor no especificó los componentes de un programa político. Sin embargo para comprender la importancia

19. Este apartado se extrae del escrito: Los congresos locales, avances sobre la autonomía indígena. En prensa por la Universidad Intercultural Indígena de Michoacán. 
de un programa político, es importante que cualquier asociación de seres humanos, en lucha por la reivindicación de sus derechos, establezca un compendio de fines u objetivos específicos, lo que es fundamental para exponer claramente la finalidad que se persigue. Así, el programa se debe generar a partir del problema específico que inició la movilización social, por lo que entonces las propuestas que se diseñen estarán destinadas, explícitamente, a incidir en las políticas gubernamentales, con una óptica alternativa a la lógica neoliberal capitalista aceptada por los estados nacionales. Con esa perspectiva es necesario establecer una serie de puntos iniciales sobre el programa político:

a) Identificar los factores que promueven la actividad social

b) Sistematización racionalizada de las aspiraciones

c) Toma de posición ideológica

d) Análisis sobre la manera de incidir en la población a través de emplear propaganda.

Ahora bien, como la base de las ideas aquí presentadas se sustenta en el estudio de los movimientos sociales actuales, es necesario agregar puntos de análisis que trasciendan las propuestas de programas políticos surgidos de los partidos políticos. Por ese motivo es necesario señalarlo, pues en primer lugar se debe de iniciar con:

a) Al identificar los factores que promueven la actividad social, también es necesario un análisis del sector productivo del que surge la movilización social. b) Presentación sistematizada de las propuestas, esto es las reformas requeridas para continuar siendo productivos, beneficiando a la mayoría de los sectores sociales involucrados.

c) La postura ideológica a adoptar, lo cual es fundamental para modelar la mentalidad de las y los integrantes y, con ello, promover un cambio de conciencia que las y los motive para trascender, esto es, ir más allá de las simples demandas del contexto.

d) La inserción del movimiento en el ámbito social, lo cual es fundamental, debido a que en muy pocas ocasiones la población apoya a las organizaciones porque no entiende el motivo de su lucha, además del hecho de que cuando se emplean bloqueos provocan malestar en amplios sectores de la población.

Ahora bien, un punto importante para que un programa político pudiese trascender, en el sentido de construir propuestas que proyecten una concepción alternativa de mundo, se requiere de una fundamentación teórica, la cual surgiría de una teoría política que considere lo propio y específico de la cultura mexicana y latinoamericana, y por qué no, contribuyendo a la emancipación humana.

Así, finalmente, para que un programa político, realmente, sea efectivo, requiere de anticiparse a las decisiones estatales. Ello se debe, a que la mayoría de las movilizaciones sociales surgen como reacción a una política pública o a una nueva ley que vulnera o afecta sus derechos y bienestar. Debido a ello, surgen de manera espontánea, sin idea clara de cómo deben actuar y sin un programa político que les ayude a negociar. Por ello, por lo general tienden a los actos 
violentos, pues es su única manera de llamar la atención de las autoridades.

De ahí la importancia que adquiere la difusión de los congresos locales de Nelson Mandela, pues es la única manera posible, al unir a los distintos sectores que conforman la población para resolver un problema y que la alternativa obtenida sea difundida a toda la población. Y que dicha actividad se repita en diversos congresos locales, cada uno de ellos tratando problemas específicos de la sociedad. Lo cual al ser comunicado a la población y buscando su apoyo, es, considero, la única manera real de incidir en la política estatal, pues se estaría estableciendo un antecedente nunca experimentado en América Latina y el Caribe, que es la creación de alternativas para mejorar las políticas estatales.

\section{Conclusiones}

La propuesta del contrapoder está destinada a crear un poder alternativo al gubernamental, el cual se llevará a cabo a través de propuestas específicas. Con base en congresos locales, en los que se discutirán las problemáticas específicas de la ciudadanía.

Así, se establecerán programas políticos que se anticiparán a los programas estatales, que por lo general afectan los derechos laborales y el bienestar de la población. Finalmente sólo resta apuntar la importancia de cambiar la forma como, hasta hoy día, se ha llevado a cabo la lucha social. 


\section{BIBLIOGRAFÍA}

Gómez Fröde, Carina. Introducción a la teoría política, México: Oxford, 2005 [Textos Jurídicos Universitarios].

Magallón Anaya, Mario. La democracia en América Latina, México: CCyDEL-UNAM-Plaza y Valdés, 2003 [Democracia y Cultura].

Marx, Karl y F. Engels. Manifiesto del Partido Comunista (1848). Digitalizado para el Marx-Engels Internet Archive por José F. Polanco en 1998. Retranscrito para el Marxists Internet Archive por Juan R. Fajardo en 1999. www.marxists.org/espanol/m-e/1840s/48-manif.htm|. Fecha de consulta 21 de mayo de 2013.

Sánchez Macgrégor, Joaquín. Ideologías políticas y poder moral. Una crítica para el contexto latinoamericano, México: UNAM, 2000.

Sánchez Vázquez, Adolfo. Filosofía de la praxis, 3a reimp., México: Siglo XXI, 2013 [Biblioteca del Pensamiento Socialista].

Serrano G., Enrique. "La relación trágica entre el poder y el valor", en Metapolítica, revista trimestral de teoría política, vol. 2, julio-septiembre 1998. 